\title{
Numerical Simulation of Flood Routing through Channels with Area Variation using Staggered Grid Method
}

\author{
Bambang Agus Sulistyono", Samijo', Aan Nurfahrudianto', Dian Devita Yohanie' ${ }^{1}$, Aprilia Dwi Handayani \\ ${ }^{1}$ Department of Mathematics Education, Faculty of Health and Science, Nusantara University PGRI Kediri, 64112, Indonesia \\ *Corresponding author: bb7agus1@unpkediri.ac.id
}

\begin{abstract}
In the event that the discharge goes to enter the channel surpasses the channel ability, than would happen floods of genuine harm to the environment around the channel. Applying the dynamic wave model, the discharge amount could be predicted in the frequent flood region if the information of discharge upstream is found out. Many numerical schemes could be utilized to discover answers to the system of differential partial equations. We proposed the usage of the staggered method to find out the solution of the system. The numerical scheme shall be used to predict the top discharge in a frequent flood region and create a flooded pocket to diminish the top discharge in the region. Based on the outcome of the numerical simulation, we may claim that a stable scheme has been created to acquire the approach resolve of the equation partial system. The staggered scheme is capable of investigating the impact of the presence of the flood pocket especially lessening the top discharge.

Keywords

Flood Routing, Dynamic Wave Model, Finite Volume Method on Staggered Grid, Prismatic and Non Primatic Channels
\end{abstract}

Received: 17 May 2021, Accepted: 24 August 2021

https://doi.org/10.26554/sti.2021.6.4.261-266

\section{INTRODUCTION}

Floods that befall a region whether metropolitan, industry, or rural could incite extreme natural harm. In general, major floods occur due to the little capacity of the channel in accommodates the incoming water into the channel. Meanwhile, the size of the capacity of the channel hangs down the wet crosssectional breadth, coarseness of the channel body, incline of the channel base, and cross-sectional breadth divided by the wet circumference. The rainy that slips in the territory will make the discharge in the channel go up (Jufriansah et al., 2020). In case the discharge augmentation goes to enter the channel outperforms the ability, at that point the water would flood of the around channel region which would have made environment breakdown and building, interfere with humane occupation and disappearance of wealth.

The discharges data that goes to enter the channel could be used to predict discharge at certain sites along the channel with the technique of flood routing. By and large, there are two sorts of flood routing methods that are every now and again used, specifically hydrology and hydraulic (Barati et al., 2012). In the first technique, the water stream variable is just counted against time so as it just predict at a particular site. This technique was created utilizing natural laws specifically the law of mass conservation. Therefore, this method simply considers the entering flow, the water storage, and the exit flow. This method possesses the deficiency significant namely not association among the geometry channel with flow variable.

In the second technique, the flow variable was counted with respect to time and space so that the flow variable may be calculated at any location throughout the channel. This technique of hydraulic was created on the law of mass conservation and the law of motion conservation which is routinely called the dynamic wave model (Saint Venant equations) (Chaudhry, 2008). Due to in course of the modeling this method associates geometry elements of the channel like the incline base channel, the harshness of the surface, and cross-sectional breadth divided by the wet circumference, length of the channel, and width of the channel. Hence, the apply of the technique hydraulic for flood routing issues are nearer to the actual condition (Chow et al., 1988).

Saint Venant equations (dynamic wave model) are exceptionally nonlinear systems and by and large, have not been discovered an analytical completion. Therefore, focus a few studies were to simplify the motion equation of the Saint Venant equations. As a result, emerged the sorts of studies models, for instance, the kinematic model (this model without : local and convective acceleration terms as well as pressure term) (Nguyen et al., 2016; Ogunlela and Adelodun, 2014; Tsai, 
2003; Zheng et al., 2020), model of dispersion (this model without : local acceleration term and convective acceleration term) (Wang et al., 2003), quasi dynamic model (this model without local acceleration) (Moramarco et al., 2008). Another focus of the research was modifying the momentum equation so that the model only applies to prismatic channels (Keskin and Ağiralioğlu, 1997; Sulistyono and Wiryanto, 2019).

Yet, in case the gauge of the district terms in the motion equation varies greatly, then the usage of a simple model can not generate precise simulations for all channel categorizes. For instance, neglecting local acceleration term, convective acceleration term, and pressure term such as in the model of kinematic, could induce valuable mistakes for be sufficient to incline channels, and also bigger coarseness coefficient values (Barati et al., 2012). Meanwhile, the focus of other study is developing certain numerical methods to resolve complete Saint Venant equations without simplification that is ordinarily called the dynamic wave model. Numerical schemes that are ordinarily applied to solve dynamic model were the characteristic scheme (Chaudhry, 2008; Chow et al., 1988; Cunge, 1980), the scheme of finite difference (Amein and Fang, 1970; Chaudhry, 2008; Nazari-Sharabian et al., 2020), the scheme of finite element (Cunge, 1980; Qureshi et al., 2014), the scheme of finite volume (Lai and Khan, 2018; Mungkasi et al., 2018), and the staggered scheme (Mungkasi et al., 2018; Pudjaprasetya, 2018; Sulistyono et al., 2020; Sulistyono and Wiryanto, 2019).

Disparate of references, this simulation of flood routing was precisely put as the opening stage constructing a flooded pocket. Thus, The study possesses two principal closely jointed goals. Initially, we observe the enormity of the top discharge at the appointed place in the prismatic channel. Next, we lessen the enormity of the top discharge at the appointed site by creates a varied flood pocket. The capability to dissimulate these various flood pockets is exceedingly beneficial in the application, particularly for overcoming flood issues. For instance, for a channel that frequently floods, we look for a location at the edges of the channel that possesses the prospect to be evolved to become a pocket of the flood. In this case, it is important to find out the data level of the top discharge lessen be resulted. Thus, this is new research for three reasons. First, developed a staggered method for solving dynamic models. Second, observation at a certain location to peak discharge in a prismatic channel. Third, lessening the peak discharge in a certain location.

\section{MATERIALS AND METHODS}

\subsection{Mathematical Model}

Mechanism of the flow in the channel might be delineated to a pair of natural laws i.e. mass conservation law and momentum conservation law (Mandailing et al., 2020). Mathematically the model might be stated into the equation of continuity and the momentum equation (Cunge, 1980), namely

$$
\partial_{t} A+\partial_{x} Q=0
$$

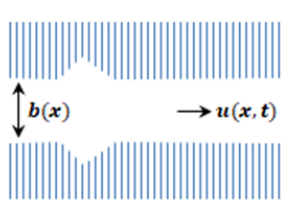

(a)

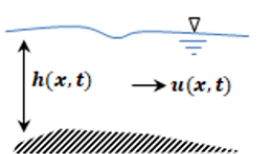

(b)

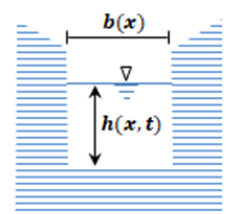

(c)
Figure 1. Sketch of Flow : (a) Sketch of the Flow Seen from Top, (b) Sketch of the Flow Move Over Topography, and (c) Sketch of Rectangular Cross-sectional

$$
\partial_{t} Q+\partial_{x}\left(\frac{Q^{2}}{A}\right)+g A \partial_{x} h+g A\left(S_{f}-S_{0}\right)=0
$$

here $A(x, t)$ indicates the cross-sectional area of the flow is perpendicular to the direction of flow, $Q(x, t)$ indicates the discharge goes into the channel, $h(x, t)$ indicates the water level above the water surface, $g$ shows the acceleration due to gravitation force, $S_{0}$ indicates the bed slope of channel, and $S_{0}$ denotes the slope due to force friction, $x$ indicates the distance in the flow direction, and $t$ indicates time needed for simulation. In this study, it is determined that the channel cross-sectional is rectangular so that the area of wet cross-sectional, $A(x, t)$ and discharge that goes into the channel, $Q(x, t)$ can be stated as

$$
\begin{aligned}
& A(x, t)=b(x) h(x, t) \\
& Q(x, t)=b(x) h(x, t) u(x, t)
\end{aligned}
$$

here $u(x, t)$ indicates velocity in flow direction whereas $b(x, t)$ indicates the width of channel.

The mechanism of the flow in the open channel with a rectangular cross-sectional could be sketched in Figure 1. Figure (a) indicates the water stream seen from the top where the water flows from the upstream towards the downstream area through the varied channel width $b(x)$. Figure (b) shown a water move by velocity $u(x, t)$ from upstream to downstream through the varies bed topography $z(x)$. Figure (c) shown a sketch of the cross-sectional seen from the front by $b(x)$ is the width of channel whereas $h(x, t)$ is the water depth. By replacing statements (3) and (4) into Equations (1) and (2), we obtain

$$
\begin{gathered}
\partial_{t} h+\partial_{x}(h u)+\frac{h u}{b} \partial_{x} b=0 \\
\partial_{t}(h u)+\partial_{x}\left(h u^{2}+\frac{1}{2} g h^{2}\right)+\frac{h u^{2}}{b} \partial_{x} b+g h\left(\partial_{x} z+S_{f}\right)=0
\end{gathered}
$$

The research model in this study is compound of Equation (5) and Equation (6) which will use to dissimulate flood routing issues in open channels. 


\subsection{Staggered Grid Scheme}

In advance of being used for simulation, two equations continuous (5) and (6) will be transformed to get difference equations using the staggered method (Pudjaprasetya, 2018). In the staggered grid scheme, flow variables which as the water depth and water velocity are calculated alternately. The water depth $h$ is calculated on the grid with an integer index while the water velocity $u$ is calculated on the grid with a fractional index as visible in Figure 2.

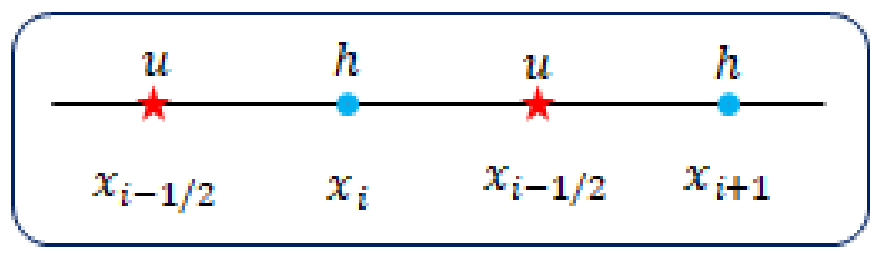

Figure 2. Placement of the Water Depth $h$ and the Water Flow Velocity $u$ in 1D Staggered Grid Scheme

Here in after, two Equations (5) and (6) will be discretized by the scheme of staggered. The produce of its discretized can be stated as

$$
\begin{gathered}
h_{i}^{j+1}=h_{i}^{j}-\Delta t\left(\frac{{ }^{*} h_{i+1 / 2}^{j} u_{i+1 / 2}^{j}{ }^{*} h_{i-1 / 2}^{j} u_{i-1 / 2}^{j}}{\Delta x}\right)-\Delta t\left(h_{i}^{j *} u_{i}^{j} \frac{b_{i+1 / 2}-b_{i-1 / 2}}{\Delta x b_{i}}\right) \\
u_{i+1 / 2}^{j+1}=u_{i+1 / 2}^{j}-\frac{\Delta t}{h_{i+1 / 2}^{j+1}}\left(\frac{q_{i+1}^{j} * u_{i+1}^{j}-q_{i}^{j} * u_{i}^{j}}{\Delta x}\right) \\
\left.-\frac{\Delta t}{h_{i+1 / 2}^{j+1}}\left(\frac{u_{i+1 / 2}^{j}\left(q_{i+1}^{j}-q_{i}^{j}\right)}{\Delta x}\right)-g \Delta t\left(\frac{h_{i+1}^{j+1}-h_{i}^{j+1}+z_{i+1}-z_{i}}{\Delta x}\right)^{j}\right) \\
-g \Delta t\left(2 h_{i+1 / 2}^{j+1}+b_{i+1 / 2}\right)^{4 / 3}\left(b_{i+1 / 2} h_{i+1 / 2}^{j+1}\right)^{-4 / 3} u_{i+1 / 2}^{j}\left|u_{i+1 / 2}^{j}\right| n^{2}
\end{gathered}
$$

for convenience, the product of $h$ by $\mathrm{u}$ is written as $h u=q$. The water depth $h$ in Equation (7) is given marker (*) because at the grids by the index of fractional there wasn't any value of $h$ so that has to be approached. The velocity of $u$ at Equation (8) was given marker $\left(^{*}\right)$ since at the grids by the index of integer there was not any value of $u$ so that has to be approached. The approach frequently applied against water depth of $h$ as well as the velocity of $u$ values was the numerical method developed by Stelling and Duinmeijer (2003), specifically

$$
{ }^{*} h_{i+1 / 2}^{j}=\left\{\begin{array}{rlr}
h_{i+1}^{j} & \text { if } & u_{i+1 / 2}^{j}<0 \\
h_{i}^{j} & \text { if } & u_{i+1 / 2}^{j} \geq 0
\end{array}\right.
$$

as well as

$$
{ }^{*} u_{i+1}^{j}=\left\{\begin{array}{lll}
u_{i+1 / 2}^{j} & \text { if } & q_{i}^{j}<0 \\
u_{i-1 / 2}^{j} & \text { if } & q_{i}^{j} \geq 0
\end{array}\right.
$$

Difference Equations (7) and (8) are will be used up for numerical simulations on the prismatic and non prismatic channels.

\section{RESULTS AND DISGUSSION}

In this part, we will be dissimulated water flow moves on prismatic and non-prismatic channels as a consequence existence of being the water flow that goes into a prismatic channel. The principal output is the top discharge information at the sighting site. Process hereinafter is lessening the discharge peak at the sighting seat by creating any pocket of the flood.

\subsection{Water Flow Observation at a Channel of Prismatic}

Given, from the upstream water goes into the prismatic channel which possesses the length of channel $L=2000$ meters with the width of channel $b=5 \mathrm{~m}$. It is recorded a triangular hydrograph data goes to enter the channel as follows.

$$
Q(0, t)=\left\{\begin{array}{rll}
3.0+\frac{9}{10} t & \text { if } & 0.0 \leq t \leq 10.0 \\
12.0-\frac{9}{10}(t-10.0) & \text { if } & 10.0 \leq t \leq 20.0 \\
\frac{3}{1} & \text { if } & t \geq 20.0
\end{array}\right.
$$

The use of the staggered scheme requires the water flow variables were stated in $\mathrm{h}$ and $u$. Therefore, we transform $Q$ into $h$ and $u$. Here, we take $u=1 \mathrm{~m} / \mathrm{s}$ so that the water depth $h$ can be expressed as

$$
Q(0, t)=\left\{\begin{array}{rll}
\frac{3}{5}+\frac{9}{50} t & \text { if } & 0.0 \leq t \leq 10.0 \\
12.0-\frac{9}{50}(t-10.0) & \text { if } & 10.0 \leq t \leq 20.0 \\
\frac{3}{5} & \text { if } & t \geq 20.0
\end{array}\right.
$$

here, the right boundary conditions are as follows: the value of $h$ at $x=2000$ is 0.61800 meters and the value of $u$ at $x=2000$ is $0.97070 \mathrm{~m} / \mathrm{s}$. For the two initial conditions, the water depth and velocity were pick up from the simplified model (Keskin and Ağiralioğlu, 1997), namely $h$ of 0.61800 meters and $u$ of $0.97070 \mathrm{~m} / \mathrm{s}$. The prismatic channel possesses a sloping base with the notation $S_{0}$ of 0.00050 , the coefficient of Manning with the notation of $n$ of 0.01380 , and the acceleration of gravity with the notation of $\mathrm{g}$ of $9.810 \mathrm{~m} / \mathrm{s}^{2}$. While the space domain is divided into 2000.0 cells, meaning that the width of the cells is set up $\Delta \mathrm{x}=1$ meter and the step of time is set up $\Delta \mathrm{t}=$ 0.1 seconds.

Figure 3 shown the discharge goes to enter the channel of prismatic which propagated throughout the region from every time unit. The quantity of discharge will lessen from time to time till the influence of the inflow is dissipated. The quantity of inflow will be damped throughout the prismatic channel as a result of the effect of rubbing among the water flow with the channel bottom and channel walls. Peak discharge will lessen with increasing distance from upstream.

Numerical simulation in this study using the help of MATLAB software. The simulation outcome in the channel of prismatic might be visible in Figure 4 , by the sighting position at $x=600$ meters. The entering flow will run into damped throughout the prismatic channel. At the sighting position $x=$ 


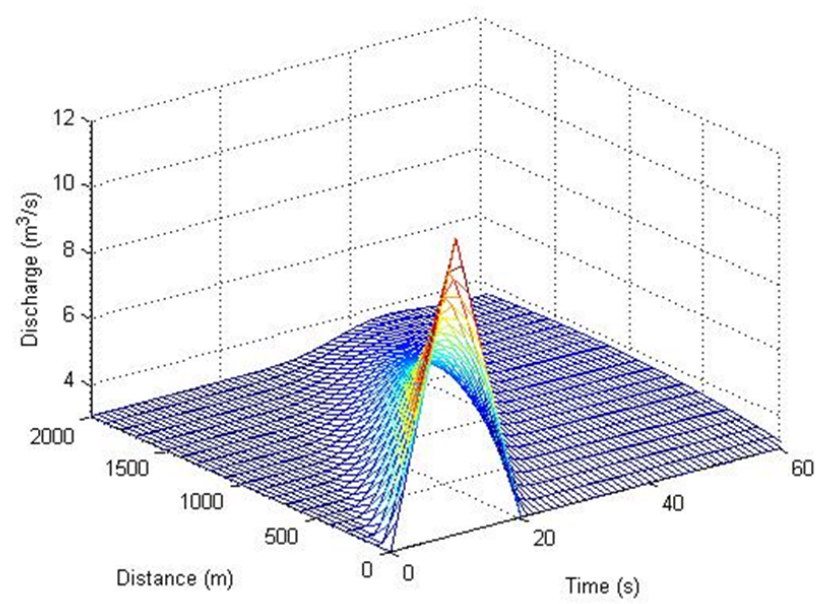

Figure 3. Discharges were Visible along the Prismatic Channel in Consequence of the Triangular Hydrograph Inflow

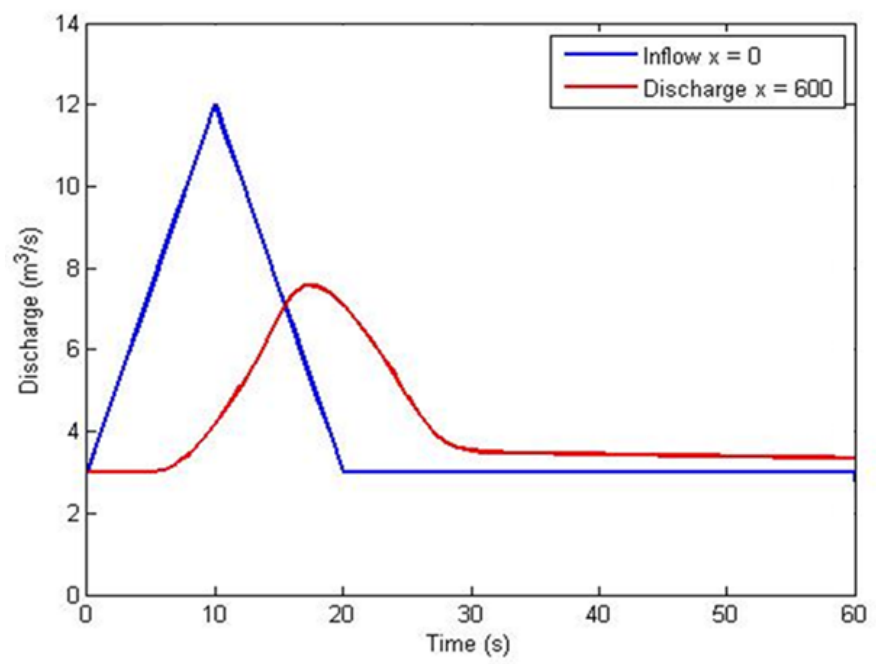

Figure 4. Denotes Comparison between the Entering Flow with the Discharge in Location $x=600$ meters

600 meters, the top discharge damped from $12.0 \mathrm{~m}^{3} / \mathrm{s}$ becomes $7.380 \mathrm{~m}^{3} / \mathrm{s}$ while the top discharge time has also shifted from $t=10$ seconds to $t=18$ seconds.

3.2 Investigation of the Influence Existence of Flood Pocket It is noted that the channel of length $L=2000$ meters is flows by water from the upstream. The triangular hydrograph data going into the channel is obtained from portion 3.1. The flood pocket width may be stated and depicted as follows

$$
b(x)=\frac{5}{2}+A_{m} \exp \left(-\left(x-\frac{150}{50}\right)^{2}\right)
$$

here in the channel boundary perceptible from above is among the functions of boundary $\frac{b(x)}{2}$ and $\frac{-b(x)}{2}$ with $A_{m}$ is varying of width the flood pocket.

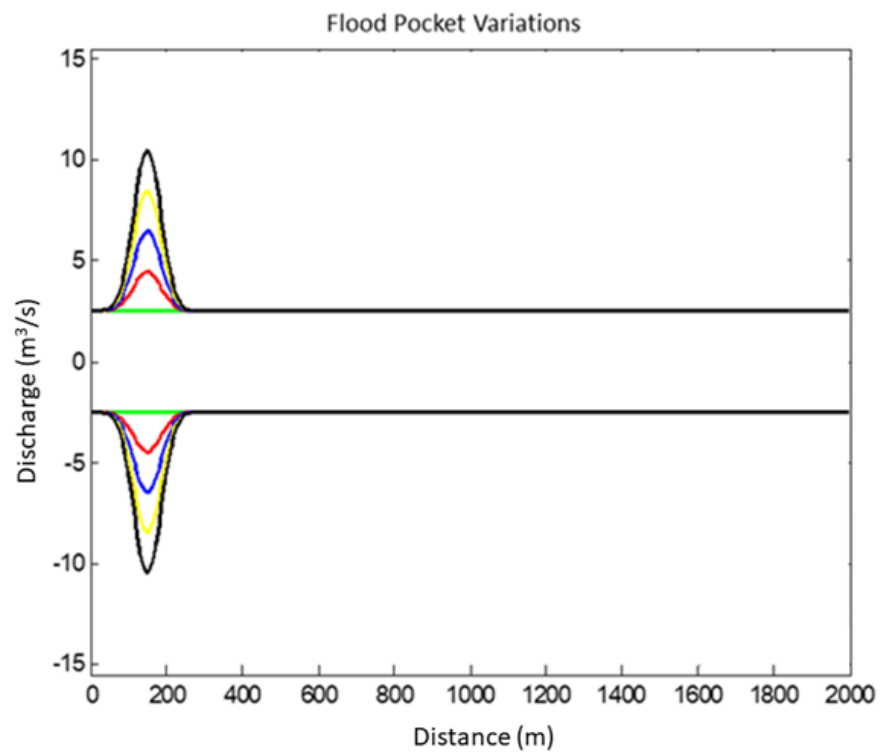

Figure 5. Profile of Pocket of Flood with Varies Width among of $A_{m}=0, A_{m}=2, A_{m}=4, A_{m}=6$, and $A_{m}=8$

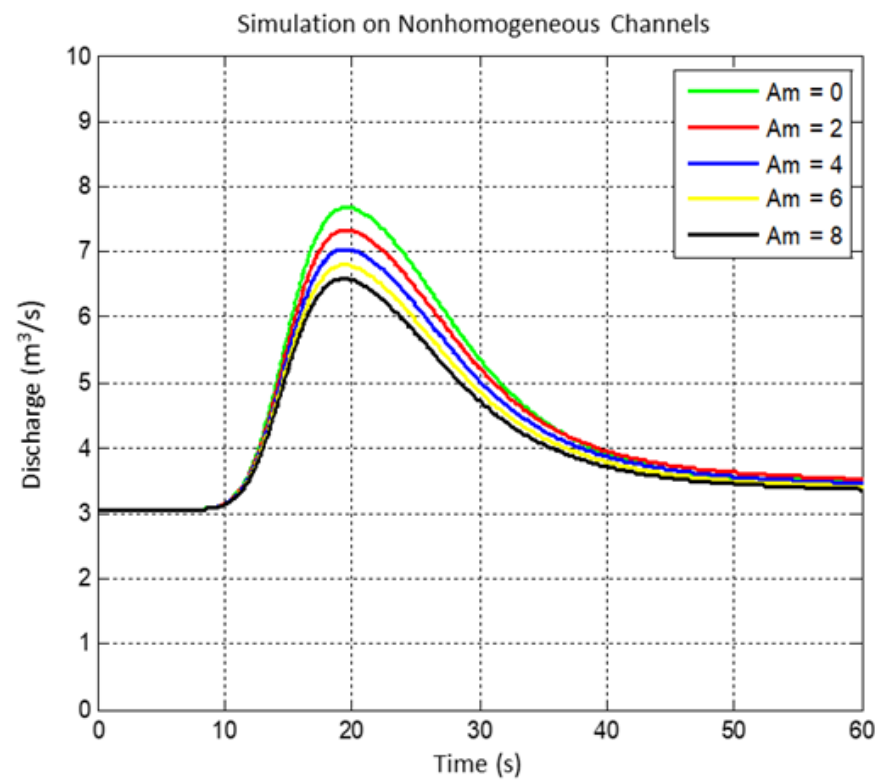

Figure 6. The Appearance Variety Top Discharge as a Result of a Variety of the Width of the Pocket of Flood

To lessen the amount of peak discharge, then at the position before the sighting location a pocket of the flood is made which is useful to collect and restrain the discharge velocity to at the sighting location occur a reduction in peak discharge. The 
varied width of the flood pocket was created at a location 150 meters from upstream (seen in Figure 5). The investigation result shown that to look at the influence of the varies of flood pockets on the peak discharge maybe were stated in Figure 6, for sighting at the location 600 meters from upstream. The top discharge is $7.8364 \mathrm{~m}^{3} / \mathrm{s}$ when $A_{m}$ equals 0 means water flow on the prismatic channel, the top discharge is $7.5645 \mathrm{~m}^{3} / \mathrm{s}$ when $A_{m}$ equals 2 , the top discharge is $7.2540 \mathrm{~m}^{3} / \mathrm{s}$ when $A_{m}$ equals 4 , the top discharge is $6.8540 \mathrm{~m} / \mathrm{s}$ when $A_{m}$ equals 6 , and the top discharge is $6.5520 \mathrm{~m}^{3} / \mathrm{s}$ when $A_{m}$ equals 8 .

By using the information on diversity at the width of flood pocket and information on the lessen in top discharge at the sighting location, then a curve can be shaped to elucidate the correlation among the top discharge as a dependent variable and the flood pocket width as an independent variable. This curve may be applied to forecast the top discharge amount in case the flood pocket width is appointed. As well as conversely, in case the top discharge is specified, then the suggested flood pocket width may be specified.

\section{CONCLUSIONS}

A staggered grid scheme has been developed to solve the Saint Venant equations (dynamic wave model) used on flow routing at the prismatic channel as well as the non-prismatic channel. We have produced a numerical scheme that is stable to getting an approximation completion of the dynamic wave model that be robust to various the width of channels. The scheme could simulate the influence of the existence of a pocket of flood in lessening the discharge top. The investigation products of flood routing on the channel show those the bigger the width of the flood pocket, then the bigger the lessen in the discharge of the top. The deficiency of the staggered method is that it is not able to simulate flood pockets in the form of a discontinuous curve. Therefore, the next research is to develop a certain numerical method to simulate flood pockets in the form of a continuous curve.

\section{ACKNOWLEDGEMENT}

The researchers would like to thank LPPM Nusantara University PGRI Kediri for supporting this research through the Penelitian Stimulus Universitas 2020.

\section{REFERENCES}

Amein, M. and C. S. Fang (1970). Implicit flood routing in natural channels. Journal of the Hydraulics Division, 96(12); 2481-2500

Barati, R., S. Rahimi, and G. H. Akbari (2012). Analysis of dynamic wave model for flood routing in natural rivers. Water Science and Engineering, 5(3); 243-258

Chaudhry, M. (2008). Open-channel flow. Springer Science and Business Media

Chow, V., D. Maidment, and L. Mays (1988). Applied Hydrology. McGraw-Hill Book Company
Cunge, J. (1980). Practical aspects of computational river hydraulics. Pitman Advanced Publishing Program

Jufriansah, A., Y. Pramudya, A. Hermanto, and A. Khusnani (2020). Surface Wave Topography using the 4 Point FDM Simulator. Science and Technology Indonesia, 5(4); 117-120

Keskin, M. E. and N. Ağiralioğlu (1997). A simplified dynamic model for flood routing in rectangular channels. Journal of Hydrology, 202(1-4); 302-314

Lai, W. and A. A. Khan (2018). Numerical solution of the Saint-Venant equations by an efficient hybrid finitevolume/finite-difference method. Journal of Hydrodynamics, $\mathbf{3 0}(2)$; 189-202

Mandailing, P. M., W. Mardiansyah, M. Irfan, A. Arsali, and I. Iskandar (2020). Characteristics of Diurnal Rainfall over Peatland Area of South Sumatra, Indonesia. Science and Technology Indonesia, 5(4); 136-141

Moramarco, T., C. Pandolfo, and V. P. Singh (2008). Accuracy of kinematic wave approximation for flood routing. II. Unsteady analysis. Journal of Hydrologic Engineering, 13(11); 1089-1096

Mungkasi, S., I. Magdalena, S. R. Pudjaprasetya, L. H. Wiryanto, and S. G. Roberts (2018). A staggered method for the shallow water equations involving varying channel width and topography. International Journal for Multiscale Computational Engineering, 16(3); 231-244

Nazari-Sharabian, M., M. Taheriyoun, and M. Karakouzian (2020). Sensitivity analysis of the DEM resolution and effective parameters of runoff yield in the SWAT model: a case study. Journal of Water Supply: Research and Technology-Aqua, 69(1); 39-54

Nguyen, T. S., T. A. Luong, H. D. Luong, and H. T. Tran (2016). A finite element one-dimensional kinematic wave rainfall-runoff model. Pacific Science Review A: Natural Science and Engineering, 18(3); 233-240

Ogunlela, A. and B. Adelodun (2014). Kinematic Parameters for Asa River Routing. International Journal of Environmental and Ecological Engineering, 8(5); 346-350

Pudjaprasetya, S. R. (2018). Transport Phenomena, equations and numerical methods. INA-Rxiv

Qureshi, A., A. Mahessar, and A. Baloch (2014). Verification and application of finite element model developed for flood routing in Rivers. International Journal of Environmental, Chemical, Ecological, Geological and Geophysical Engineering, 8(2); 86-89

Stelling, G. S. and S. A. Duinmeijer (2003). A staggered conservative scheme for every Froude number in rapidly varied shallow water flows. International Journal for Numerical Methods in Fluids, 43(12); 1329-1354

Sulistyono, B. and L. Wiryanto (2019). A Staggered Method for Numerical Flood Routing in Rectangular Channels. Advances and Applications in Fluid Mechanics, 23(2); 171-179

Sulistyono, B., L. Wiryanto, and S. Mungkasi (2020). A staggered method for simulating shallow water flows along channels with irregular geometry and friction. International Journal on Advanced Science, Engineering and Information Technol- 
ogy, 10(3); 952-958

Tsai, C. W. (2003). Applicability of kinematic, noninertia, and quasi-steady dynamic wave models to unsteady flow routing. Journal of Hydraulic Engineering, 129(8); 613-627

Wang, G.-T., S. Chen, J. Boll, and V. Singh (2003). Nonlinear convection-diffusion equation with mixing-cell method for channel flood routing. Journal of Hydrologic Engineering, 8(5); 259-265

Zheng, H., E. Huang, and M. Luo (2020). Applicability of Kinematic Wave Model for Flood Routing under Unsteady Inflow. Water, 12(9); 2528 